\title{
Role of inflammatory mediators (TNF- $\alpha$, IL-6, CRP), biochemical and hematological parameters in type 2 diabetes mellitus patients of Kashmir, India
}

\author{
Haamid Bashir ${ }^{1}$, Showkat Ahmad Bhat ${ }^{2}$, Sabhiya Majid*1(D), Rabia Hamid ${ }^{3}$, Rakesh K Koul ${ }^{4}$, Muneeb U Rehman ${ }^{1}$, \\ Insha Din $^{1}$, Javaid Ahmad Bhat ${ }^{1}$, Jasiya Qadir ${ }^{1}$, Akbar Masood $^{3}$
}

Received: 1 May 2019

Published: 12 Feb 2020

\section{Abstract}

Background: Type II Diabetes mellitus (T2DM) is a multifactorial disease and a leading cause of premature deaths. Inflammatory cytokines are reported that they have potential to enhance insulin resistance and hence T2DM. Assessment of immunological profile in T2DM patients of Kashmir valley is unclear. So, detection of cytokines is relevant to determine the extent and direction of immune responses. The current research was taken to study the role of inflammatory mediators in T2DM along with insulin sensitivity, biochemical and hematological parameters in mountainous valley of Kashmiri population.

Methods: A total of 340 subjects were selected in this study among them 160 were T2DM cases and 180 were healthy controls. Serum expression of inflammatory mediators (TNF- $\alpha$ and IL-6 ) were quantified by ELISA technique, WBC count was measured on Sysmax (Germany) hematology analyzer, biochemical and Immunoassay parameters were done on Abbott c4000 (USA) and Abbott C1000 (USA) fully automatic analyzer. Data was analyzed using statistical 'software SPSS 16.1' (Chicago, IL). For all assessments, $\mathrm{p}<0.05$ were considered statistically significant.

Results: The expressions of candidate cytokines (TNF- $\alpha$, IL-6, CRP, and WBC) were highly significant ( $\mathrm{p}<0.001)$ in T2DM. Among inflammatory mediators, TNF- $\alpha$ shows a positive correlation $(\mathrm{p}<0.001)$ with glycemic profile and insulin sensitivity in T2DM cases in comparison with healthy normal. Biochemical (fasting sugar, HbAlc, insulin resistance, lipid profile) and anthropometric (BMI) parameters were highly significant $(\mathrm{p}<0.001)$ in $\mathrm{T} 2 \mathrm{DM}$ cases as compared to non-diabetic normal.

Conclusion: Low grade inflammation and up regulation of inflammatory mediators has been purported to play a significant role in pathogenesis of T2DM. Our findings confirm that positive correlation of TNF- $\alpha$ and IL-6 with T2DM and insulin sensitivity. These can act as early prediction biomarkers of T2DM. Further studies on wider range of pro and anti- inflammatory cytokines i.e. mediators, in association with other biochemical, immunoassay and hematological parameters are needed to help clinicians manage and treat T2DM effectively.

Keywords: Inflammation, Biomarkers, Cytokines, Kashmir, Mediators, Adult onset type 2 diabetes mellitus, SMHS.

Conflicts of Interest: None declared

Funding: The research was supported by the Department of Biochemistry (Research centre-University of Kashmir), GMC Srinagar.

*This work has been published under CC BY-NC-SA 1.0 license.

Copyright $\subseteq$ Iran University of Medical Sciences

Cite this article as: Bashir H, Ahmad Bhat Sh, Majid S, Hamid R, Koul RK, Rehman MU, Din I, Ahmad Bhat J, Qadir J, Masood A. Role of inflammatory mediators (TNF- $\alpha$, IL-6, CRP), biochemical and hematological parameters in type 2 diabetes mellitus patients of Kashmir, India. Med $J$ Islam Repub Iran. 2020 (12 Feb);34:5. https://doi.org/10.47176/mjiri.34.5

Corresponding author: Dr Sabhiya Majid, biochemistrygmcsrinagar@gmail.com, zululubaba@gmail.com

\footnotetext{
Department of Biochemistry, Govt. Medical College Srinagar, Research CentreUniversity of Kashmir, Srinagar, India

2. Department of Biochemistry, Govt. Medical College Doda, Kashmir, India

3. Department of Biochemistry, University of Kashmir, Srinagar, India

4. Sheri-Maharaja Hari Singh Hospital (SMHS) \& Associated Hospitals Govt.

Medical College, Srinagar, Kashmir, India.
}

$\uparrow$ What is "already known" in this topic:

Effect of the pro and anti-inflammatory cytokines like (TNF- $\alpha$, IL-6, CRP) has been reported in insulin signaling pathways, cross-linking and ultimately developing insulin resistance in $\beta$-cells of pancreas which further risks to T2DM. Stability among these Pro and anti-inflammatory cytokines is necessary to make $\beta$-cells immune to any infection which may lead to T2DM.

\section{$\rightarrow$ What this article adds:}

Our experimental findings provide evidence that the pattern and variation of these cytokines (TNF- $\alpha$, IL-6, CRP, and WBC) are important in the pathogenesis of T2DM. The significant correlation of these inflammatory mediators in T2DM cases with glycemic profile and insulin sensitivity leads to the pathogenesis of diseases in this ethnic population. These findings confirms that TNF- $\alpha$, IL-6, plays a positive role in the pathogenesis of T2DM in this ethnic population of Kashmir and can act as an early prediction biomarkers. 


\section{Introduction}

Type II diabetes mellitus (T2DM) is a noncommunicable, chronic disorder and progresses slowly because of multifactorial etiology. T2DM is a leading cause of premature deaths worldwide, and its exceptional upsurge poses a severe threat and imposes a huge economic burden worldwide (825 billion dollars per year) (1). According to a recent estimation of the World Health Organization (WHO), 422 million people globally are affected from diabetes with a prevalence rate of $8.5 \%$ and $46.3 \%$ still remains undiagnosed and the number is projected to rise to 552 million in 2030. Furthermore, the maximum percentage lives in developing countries and comprises of 40-60 age group. In 2017 it was reported that India alone has 72 million people affected with T2DM and is projected to rise to 101.2 million in 2030 (2, $3)$. Most of the Indian populations are unaware of that disease. The risk factors of T2DM are suggestively increased with changing lifestyle, blood pressure, central obesity, inadequate physical activity and unhealthy diet (4).

Fasting Blood glucose (FBG), 2-hour postprandial blood glucose (2hr-PP) and glycated hemoglobin (HbAlc) levels are most widely used as glycemic control markers which indicates the progression of the disease and development of its complications. T2DM is reported to be linked with lipid and lipoprotein irregularities, including reduced HDL cholesterol and raised triglycerides. (5-8). Trend of T2DM is changed from metabolic disorder to inflammation as effects of the pro and anti-inflammatory cytokines like tumor necrosis factor alpha (TNF- $\alpha$ ), interleukin-6 (IL-6) and C-reactive protein (CRP) has been reported in insulin signaling pathways, cross-linking and ultimately developing insulin resistance in $\beta$-cells of pancreas which further risks to T2DM (9-11). Stability among these pro and anti-inflammatory cytokines is necessary to make $\beta$-cells immune to any infection which may lead to T2DM $(12,13)$. Some studies had reported high levels of CRP in T2DM as an independent biomarker for T2DM (12-16). The cytokines like TNF- $\alpha$ and IL-6 are expressed higher levels in activated macrophages and proinflammatory cytokine-like TNF- $\alpha$ induces insulin resistance by inhibiting phosphorylation of IRS-1 and Akt substrate 160 on insulin signaling cascade pathways (17). Ibfelt et al., also reported that TNF- $\alpha$ is decreasing in insulin production from $\beta$-cells of the pancreas, and suggests it as a possible marker which mediates the balance between insulin resistance and diabetes mellitus (18). Interleukin-6 (IL-6) is an inflammatory cytokine with multifunctional biologic effects. Few studies reported that it has an association with the pathogenesis of T2DM $(19,20)$. On the other hand, many studies suggest that IL-6 has a dual role of anti-inflammatory and improves glucose metabolism in T2DM patients $(20,21)$. IL-6 has a great impact on glucose homeostasis and metabolism by acting indirectly on the $\beta$-cells of the pancreas and on adipocytes (21-24). However, its role as an early biomarker for T2DM is still doubted and more such studies are needed in different populations. Many studies were conducted to assess the correlation of inflammatory markers with T2DM in other populations of the world; they reported significant association of these inflammatory markers (IL-6, TNF- $\alpha$ ) (2528). Kashmir valley is a division of Jammu and Kashmir State of India, which is mostly hilly and surrounded by snow-clad mountains. People of the valley are different in culture and food habits as compared to other states of India. Rice (Oryza sativa; carbohydrate diet) is a staple food of this region. Rapid urbanization and sedentary lifestyle of people are believed to be risk factors which leads to the pathogenesis of T2DM in this region $(29,4)$. A recent study done by the Indian Council of Medical Research (ICMR) reported that there was a prevalence of $6.1 \%$ of T2DM patients in Kashmir (30). Presently, no such study has been carried out on these inflammatory mediators (IL6 , TNF- $\alpha$, CRP and WBC) and their association with T2DM in Kashmiri ethnic population. Hence, we hypothesized to study the role of these inflammatory mediators (IL-6 and TNF- $\alpha$, CRP, WBC), biochemical and hematological parameters in T2DM cases and controls in association with glycemic profile and Insulin sensitivity in the people of the mountainous valley of Kashmir, India.

\section{Methods}

This study was conducted in Government Medical College (GMC) Srinagar at the Department of Biochemistry (Research centre- University of Kashmir) from September 2017 to January 2019.

\section{Subjects}

A total of 340 subjects were included in the study. The T2DM cases and healthy controls were enrolled for the study from OPD/IPD of the Sheri-Maharaja Hari Singh (SMHS) Hospital, and Associated Hospitals GMC Srinagar. Among 340 subjects, 160 T2DM patients were finally enrolled in the study. They were diagnosed as per standard of the American Diabetes Association (ADA) criteria 2016 (Table 1) and 180 healthy individuals (age-sex matched) were taken as sample controls. The study procedure and informed consent were reviewed by the ethics committee of GMC, Srinagar under Ref no. 89/ETH/GMC/ICMR as per Helsinki declaration. Written informed consent in local (Urdu/Kashmiri) and working language (English) with questionnaire response from patients and healthy controls was documented and the records were maintained as per hospital protocol.

Inclusion criteria: Patients of Kashmiri ethnicity, confirmed diagnosis of T2DM over two years.

Exclusion criteria: Non-Kashmiri origin, pregnant women, patients suffering from thyroiditis, rheumatoid

Table 1. American Diabetes Association (ADA) 2016 Criteria for Diagnosing T2DM

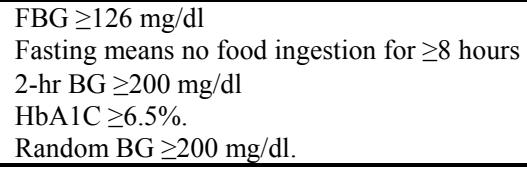


Weight $(\mathrm{kg})$ was measured by a digital weighing machine. The body mass index (BMI) of subjects was calculated by formulae $=$ weight $(\mathrm{Kg}) /$ height $\left(\mathrm{m}^{2}\right)$. Participants with a BMI of $\geq 30.0 \mathrm{~kg} / \mathrm{m} 2$ were considered obese as per NCEP ATPIII criteria. "Waist circumference" (WC) was evaluated in the middle, between the lower rib margin and the iliac crest with subjects in the upright position.

\section{Criteria for Sample size}

Sample size was calculated to detect an effect size of 0.10 at type 1 error of $50 \%$ and power of $80 \%$ using "G Power version 3.1.9.2". Given the above parameters, a total size of 340 (160 in T2DM and 180 in controls in each group) will be sufficient for this study.

\section{Sample collection and separation}

Five $\mathrm{ml}$ blood was collected by phlebotomists by venipuncture from patients and healthy controls at the common collection centre facility of Government ShriMaharaja Hari Singh Hospital (SMHS), Srinagar. The patients and healthy controls were recruited from the OutPatient Department (OPD)/ In-Patient Department (IPD) of Post Graduate Department of Medicine, GMC, Srinagar. Blood was immediately transferred into $3 \mathrm{ml}$ green top heparin vial and $2 \mathrm{ml}$ blood into Purple top EDTA vial. Heparinized $3 \mathrm{ml}$ blood was centrifuged at 4000 RPM for 2 minutes and plasma was aliquoted into Eppendorf tubes for ELISA and other biochemical analysis stored at $-20^{\circ} \mathrm{c}$ till further analysis.

\section{Biochemical and Immunoassay Analysis}

Glycated hemoglobin (HbA1c) levels and Biochemistry were determined for all patients and healthy controls at the clinical Laboratory of Department of Biochemistry, GMC, Srinagar on Abbott c4000 auto-analyzer (USA). CRP and Insulin assay were done on a fully automatic immunoassay analyzer (Abbott c1000). The Insulin resistance (IR) of subjects was documented by calculating the index of HOMA-IR (homeostatic model assessment - insulin resistance) using this method: "HOMA-IR = fasting insulin $(\mu \mathrm{U} / \mathrm{ml}) \times$ fasting glucose $(\mathrm{mg} / \mathrm{dl}) / 405 "$ (24). Following HOMA-IR score was used as a reference range for classification of IR.

$<3=$ Normal IR

c) $>5=$ Severe IR

b) Between 3 and $5=$ Moderate IR

Hematological analysis: Whole blood samples taken in EDTA vials were analyzed for WBC count on Sysmax hematology analyzer (Germany).
Enzyme-linked Immunoassay (ELISA) Analysis

TNF- $\alpha$ assay: Quantitative measurement of TNF- $\alpha$ was done by the 'Diaclone Human TNF- $\alpha$ ELISA kit' (Catalogue No. 950.090.09, France). The minimum measurable concentration was estimated to be $8 \mathrm{pg} / \mathrm{ml}$. The coefficient of variation for TNF- $\alpha$ was $3.3 \%$ and $9.0 \%$ (intra and inter-assay) respectively. The subsequent washing and absorbance reading were done on microplate reader Lablifeer/ew 2007(Germany). Samples were tested in triplicate and a calibration curve was added to each plate.

IL-6 assay: Quantitative measurement of IL-6 was done by use of a commercial ELISA kit; 'Diaclone Human IL-6 ELISA kit' (Catalogue No. 950.030.096, France). The minimum measurable concentration was estimated to be $2 \mathrm{pg} / \mathrm{ml}$. The coefficient of variation for IL-6 was $3.6 \%$ and $7.7 \%$ (intra and inter-assay), respectively. The subsequent washing and absorbance reading were done on microplate reader Lablifeer/ew 2007(Germany). Samples were tested in triplicate and a calibration curve was added to each plate.

\section{Statistical analysis}

Data was inserted on Microsoft excel 2011 spreadsheet. All the data were expressed as a mean \pm standard deviation and significance value (p) were calculated. Data analysis was performed by using statistical 'software SPSS 16.1' (Chicago, IL). Students' T-test was done on biochemical, immunoassay and inflammatory mediators. Chisquare test was done on socio-demographic characters. Correlation analysis was performed for determining the association between serum IL-6, TNF- $\alpha$, CRP and WBC levels and Pearson correlation coefficient ( $r$ ) was obtained. For all assessments, $\mathrm{p}<0.05$ were considered statistically significant.

\section{Results}

\section{Anthropometric analysis of the study group}

Table 2 summarizes the Anthropometric characteristics of 340 subjects, including 160 prevalent T2DM cases and 180 healthy controls. The mean \pm SD age of T2DM patients was $48.9 \pm 8.4$ years, and that of controls was $44.9 \pm 9.8$ years which is statistically significant $(p=0.002)$. It was observed that in T2DM patients, mean \pm SD of BMI was $41.2 \pm 7.1 \mathrm{~kg} / \mathrm{m} 2$ and in healthy controls was $20.2 \pm 2.2$ $\mathrm{kg} / \mathrm{m} 2$ which is statistically significant $(\mathrm{p}=0.001)$. There was no significance $(p=0.472)$ found in waist circumference (WC) within T2DM patients and healthy controls. Among 160 cases, 81 were males and 79 females and in healthy controls, 94 were males and 86 were females, on gender-wise comparison difference in patients and controls are non-significant $(\mathrm{p}=0.829)$.

Table 2. Anthropometric analysis of T2DM cases and Controls

\begin{tabular}{lccc}
\hline Variables & $\begin{array}{c}\text { T2DM Cases } \\
(\mathrm{n}=160)\end{array}$ & $\begin{array}{c}\text { Controls } \\
(\mathrm{n}=180)\end{array}$ \\
\hline Age (Years) & $48.9 \pm 8.4$ & $44.9 \pm 9.8$ & P value \\
Sex (M/F) & $81 / 79$ & $94 / 86$ & 0.002 \\
BMI (kg/m2) & $41.2 \pm 7.1$ & $20.2 \pm 2.2$ & 0.829 \\
WC(Inches) & $47.4 \pm 4.6$ & $29.2 \pm 4.5$ & 0.001 \\
\hline Data are presented as means \pm SD. The significance of the difference is based on the one-way T-test. "BMI: Body mass index; WC: Waist Circumference."
\end{tabular}




\section{Socio-demographic profile of the study group}

Social class scale is based on Residence, Smoking, Lifestyle and Education items. $43.1 \%$ of the T2DM patients were urban and $56.8 \%$ belongs to the rural population, while among healthy controls, $41.6 \%$ were urban, and $58.3 \%$ belongs to the rural population. $31.2 \%$ of the T2DM patients were smokers and $68.7 \%$ were nonsmokers, while among healthy controls, $2.7 \%$ were smokers and $97.2 \%$ were non-smokers. $31.2 \%$ of the T2DM patients were active and $68.7 \%$ were sedentary, while among healthy controls, $58.3 \%$ were active and $41.6 \%$ were sedentary. $36.8 \%$ of the T2DM patients were literate and $63.1 \%$ were illiterate, while among healthy controls, $55.0 \%$ were literate, and $45.0 \%$ were illiterates.

\section{Biochemical profile of the study group}

The biochemical profile of T2DM cases and healthy controls was summarized in Table 3 and showed that there was an increasing trend in parameters of lipid profile like serum Triglycerides (TG), total cholesterol (TC), Low Density Lipoprotein (LDL) and High Density Lipoprotein (HDL) among T2DM cases as compared to healthy controls and the trend were significantly high $(\mathrm{p}<0.05)$. The glycemic profile (Glucose Fasting and HbA1c) in T2DM cases was higher as compared to healthy controls and are found to be statistically significant $(\mathrm{p}<0.05)$.

\section{Immunoassay profile of study group}

Table 4 showed Immunoassay profile of the study group where there was an elevation in the Insulin $(\mu \mathrm{U} / \mathrm{ml})$ levels among T2DM case (32.6 \pm 7.5$)$ as compared to healthy controls $(7.8 \pm 2.1)$ and it was found that the elevation level among the T2DM cases was significantly $(\mathrm{p}=0.001)$ higher than healthy controls. The HOMA-IR index for insulin sensitivity was calculated by a standard formula in both T2DM cases and healthy controls and was found significantly $(\mathrm{p}<0.05)$ higher in T2DM cases.

\section{Immunological profile of study group}

Table 5 describes the levels of serum inflammatory mediators (IL-6, TNF- $\alpha$, CRP and WBC) in T2DM cases and healthy controls; the mean $\pm \mathrm{SD}$ value of inflammatory markers in T2DM cases was TLC $=8395 \pm 1843$ IL$6=19.2 \pm 7.2$, TNF $-\alpha=34.5 \pm 8.8$ and $\mathrm{CRP}=4.2 \pm 0.9$ while in healthy controls it was TLC $=7289 \pm 1404$, IL-6 $=3.0 \pm 1.4$, TNF $-\alpha=12.7 \pm 3.4$ and $C R P=1.4 \pm 0.6$; and it was found that in T2DM patients the levels of inflammatory mediators were highly significant $(p<0.05)$ in comparison with healthy controls.

\section{Comparison of Inflammatory mediators in the study} group

Table 6 shows the comparison of inflammatory mediators within gender groups and it was found that in female

\begin{tabular}{|c|c|c|c|}
\hline Variables & $\begin{array}{c}\text { Diabetes mellitus } \\
(\mathrm{n}=160)\end{array}$ & $\begin{array}{l}\text { Controls } \\
(\mathrm{n}=180)\end{array}$ & $\mathrm{P}$ value \\
\hline Glucose Fasting (mg/dl) & $166.4 \pm 31.9$ & $80.9 \pm 6.8$ & 0.111 \\
\hline Post-parandial (mg/dl) & $314.2 \pm 50.9$ & $121.1 \pm 8.2$ & 0.001 \\
\hline Cholesterol (mg/dl) & $296.5 \pm 53.3$ & $107.1 \pm 26.8$ & 0.001 \\
\hline Triglycerides (mg/dl) & $318.5 \pm 56.3$ & $145.1 \pm 29.4$ & 0.001 \\
\hline $\mathrm{HDL}(\mathrm{mg} / \mathrm{dl})$ & $91.4 \pm 21.7$ & $51.9 \pm 11.0$ & 0.021 \\
\hline $\mathrm{LDL}(\mathrm{mg} / \mathrm{dl})$ & $147.3 \pm 8.0$ & $68.8 \pm 28.9$ & 0.001 \\
\hline $\mathrm{HbA} 1 \mathrm{c}(\%)$ & $9.8 \pm 2.8$ & $4.7 \pm 0.8$ & 0.011 \\
\hline
\end{tabular}

Data are presented as means \pm SD. The significance of the difference is based on the one-way T-test. HbA1c: Hemoglobin A1C

Table 4. Immunoassay analysis of study group

\begin{tabular}{|c|c|c|c|}
\hline Parameters & $\begin{array}{c}\text { Diabetes mellitus } \\
(\mathrm{n}=160)\end{array}$ & $\begin{array}{l}\text { Controls } \\
(\mathrm{n}=180)\end{array}$ & $\begin{array}{l}\mathrm{P} \text { value } \\
(<0.05)\end{array}$ \\
\hline Insulin $(\mu \mathrm{U} / \mathrm{ml})$ & $32.6 \pm 7.5$ & $7.8 \pm 2.1$ & 0.001 \\
\hline HOMA-IR & $13.5 \pm 4.7$ & $1.5 \pm 0.5$ & 0.001 \\
\hline
\end{tabular}

Data are presented as means \pm SD. The significance of the difference is based on the one-way T-test. $\mathrm{p}$ value $<0.05$ are statistically significant

Table 5. Inflammatory mediators in the study group

\begin{tabular}{|c|c|c|c|}
\hline Variables & $\begin{array}{c}\text { Diabetes mellitus } \\
\quad(n=160)\end{array}$ & $\begin{array}{c}\text { Controls } \\
(\mathrm{n}=180)\end{array}$ & $\begin{array}{l}\mathrm{P} \text { value } \\
(<0.05)\end{array}$ \\
\hline TLC (thousands) & $8395 \pm 1843$ & $7289 \pm 1404$ & 0.001 \\
\hline IL-6 (pg/ml) & $19.2 \pm 7.2$ & $3.0 \pm 1.4$ & 0.001 \\
\hline TNF- $\alpha(\mathrm{pg} / \mathrm{ml})$ & $34.5 \pm 8.8$ & $12.7 \pm 3.4$ & 0.001 \\
\hline $\mathrm{CRP}(\mathrm{mg} / \mathrm{dl})$ & $4.2 \pm 0.9$ & $1.4 \pm 0.6$ & 0.001 \\
\hline
\end{tabular}

sis factor-Alpha; IL-6: Interleukin-6; CRP: C - reactive protein

Table 6. Comparison of Inflammatory mediators in T2DM Male and Female patients versus control subjects

\begin{tabular}{|c|c|c|c|c|c|}
\hline $\begin{array}{l}\text { Inflammatory } \\
\text { Mediators }\end{array}$ & $\begin{array}{c}\text { Male T2DM } \\
(\mathrm{n}=81)\end{array}$ & $\begin{array}{c}\text { Female T2DM } \\
(\mathrm{n}=79)\end{array}$ & $\begin{array}{c}\text { Male controls } \\
(\mathrm{n}=94)\end{array}$ & $\begin{array}{c}\text { Female controls } \\
(\mathrm{n}=86)\end{array}$ & $\begin{array}{l}\mathrm{P} \text { value } \\
<0.05\end{array}$ \\
\hline TNF- $\alpha(\mathrm{pg} / \mathrm{dl})$ & $8.4 \pm 0.9$ & $8.9 \pm 1.0$ & $3.5 \pm 0.3$ & $3.3 \pm 0.3$ & 0.000 \\
\hline IL-6 (pg/dl) & $6.8 \pm 0.7$ & $7.6 \pm 0.8$ & $1.4 \pm 0.1$ & $1.4 \pm 0.1$ & 0.000 \\
\hline CRP (mg/dl) & $0.8 \pm 0.1$ & $1.0 \pm 0.1$ & $0.6 \pm 0.06$ & $0.6 \pm 0.06$ & 0.000 \\
\hline WBC (thousands) & $1944 \pm 216$ & $1741 \pm 195$ & $1448 \pm 149$ & $1350 \pm 145$ & 0.072 \\
\hline
\end{tabular}


cases levels of inflammatory mediators was highly significant $(\mathrm{p}<0.05)$ as compared to male cases while WBC was not statistically significant, which provides us the information that females may be at higher risk to T2DM.

\section{Correlation of inflammatory mediators in the study} group

Figure 1 (a) to 1 (d) show the correlation of inflammatory mediators in T2DM cases and controls with glycemic profile and insulin sensitivity and was studied by Pearson's correlation analysis. TNF- $\alpha$ shows a positive correlation with the glycemic profile (Glucose fasting, HbAlc) and insulin sensitivity (Insulin assay, HOMA-IR) in

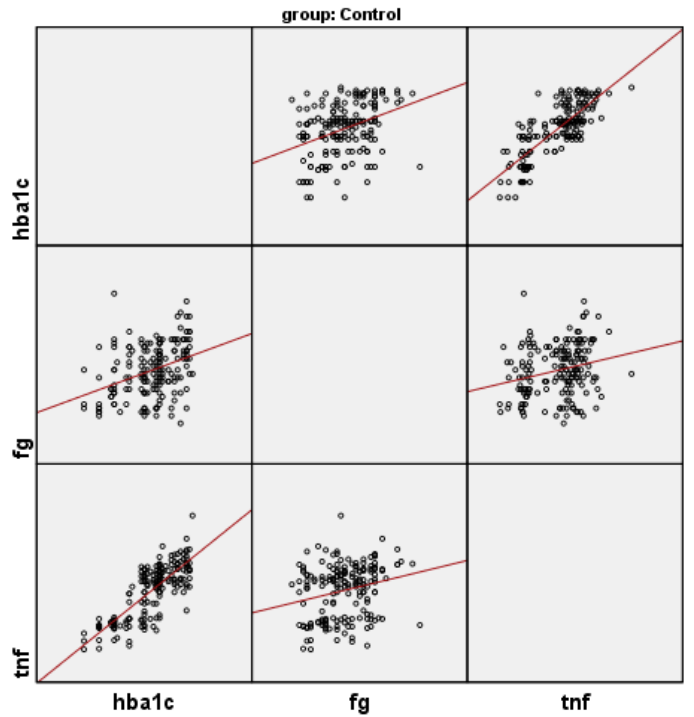

Fig. 1. (a) .Correlation of TNF- $\alpha$ with glycemic profile in controls
T2DM cases and were statistically significant $(\mathrm{p}<0.05)$.

\section{Correlation of inflammatory mediators in the study} group with gender-wise

Table 7 describes the association of inflammatory mediators with glycemic profile and Table 8, depicts the association of insulin sensitivity as per gender-wise in cases and controls. We observed in males and female T2DM cases that there was a positive correlation $(p=0.001)$ of TNF- $\alpha$ with glycemic profile and insulin sensitivity and other inflammatory mediators show negative and weak correlation.

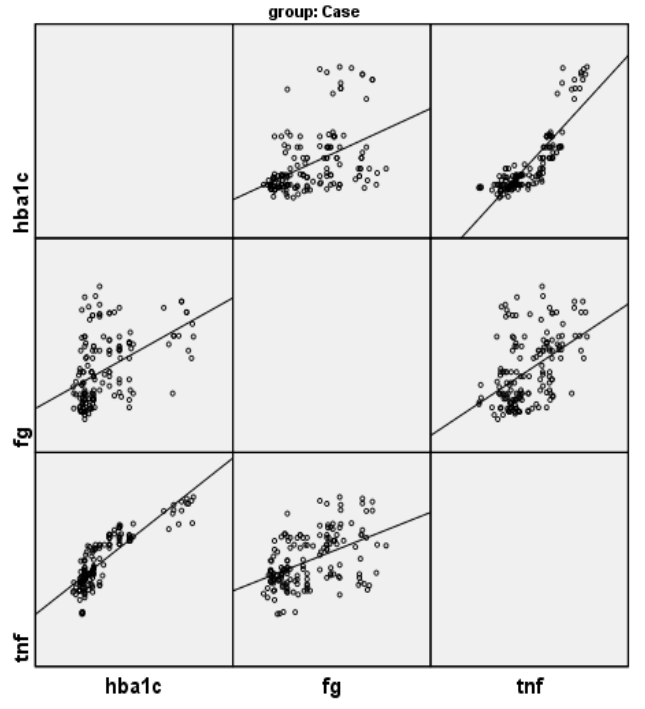

Fig. 1. (b). Correlation of TNF- $\alpha$ with glycemic profile in cases

Table 7. Pearson correlation coefficients of inflammatory mediators with glycemic profile, sex-wise

\begin{tabular}{|c|c|c|c|c|c|c|c|c|}
\hline \multirow[b]{3}{*}{ Inflammatory Mediators } & \multicolumn{4}{|c|}{ Cases } & \multicolumn{4}{|c|}{ Controls } \\
\hline & \multicolumn{2}{|c|}{ HBA1c } & \multicolumn{2}{|c|}{ Fasting Glucose } & \multicolumn{2}{|c|}{ HBA1c } & \multicolumn{2}{|c|}{ Fasting Glucose } \\
\hline & $\begin{array}{c}\text { Males } \\
\mathrm{n}=81\end{array}$ & $\begin{array}{c}\text { Females } \\
n=79\end{array}$ & $\begin{array}{c}\text { Males } \\
n=81\end{array}$ & $\begin{array}{c}\text { Females } \\
n=79\end{array}$ & $\begin{array}{c}\text { Males } \\
\mathrm{n}=94\end{array}$ & $\begin{array}{c}\text { Females } \\
n=86\end{array}$ & $\begin{array}{c}\text { Males } \\
\mathrm{n}=94\end{array}$ & $\begin{array}{c}\text { Females } \\
\mathrm{n}=86\end{array}$ \\
\hline \multirow[t]{2}{*}{ TNF- $\alpha$} & $* \mathrm{p}=0.002$ & $\mathrm{p}=0.004$ & $\mathrm{p}=0.005$ & $\mathrm{p}=0.006$ & $* \mathrm{p}=0.025$ & $\mathrm{p}=0.010$ & $\mathrm{p}=0.012$ & $\mathrm{p}=0.053$ \\
\hline & $* \mathrm{r}=0.849$ & $\mathrm{r}=0.873$ & $\mathrm{r}=0.456$ & $\mathrm{r}=0.536$ & $* \mathrm{r}=0.328$ & $\mathrm{r}=0.358$ & $\mathrm{r}=0.259$ & $\mathrm{r}=0.210$ \\
\hline \multirow[t]{2}{*}{ IL-6 } & $\mathrm{p}=0.039$ & $\mathrm{p}=0.125$ & $\mathrm{p}=0.112$ & $\mathrm{p}=0.062$ & $\mathrm{p}=0.145$ & $\mathrm{p}=0.082$ & $\mathrm{p}=0.829$ & $\mathrm{p}=0.830$ \\
\hline & $\mathrm{r}=0.230$ & $\mathrm{r}=0.174$ & $\mathrm{r}=0.178$ & $\mathrm{r}=0.211$ & $\mathrm{r}=0.162$ & $\mathrm{r}=0.188$ & $\mathrm{r}=0.023$ & $\mathrm{r}=0.023$ \\
\hline \multirow[t]{2}{*}{ CRP } & $\mathrm{p}=0.006$ & $\mathrm{p}=0.963$ & $\mathrm{p}=0.971$ & $\mathrm{p}=0.723$ & $\mathrm{p}=0.238$ & $\mathrm{p}=0.011$ & $\mathrm{p}=0.743$ & $\mathrm{p}=0.044$ \\
\hline & $\mathrm{r}=0.304$ & $\mathrm{r}=0.001$ & $\mathrm{r}=0.004$ & $\mathrm{r}=0.041$ & $\mathrm{r}=0.021$ & $\mathrm{r}=0.365$ & $\mathrm{r}=0.034$ & $\mathrm{r}=0.218$ \\
\hline \multirow[t]{2}{*}{ WBC } & $\mathrm{p}=0.224$ & $\mathrm{p}=0.811$ & $\mathrm{p}=0.033$ & $\mathrm{p}=0.905$ & $\mathrm{p}=0.050$ & $\mathrm{p}=0.041$ & $\mathrm{p}=0.433$ & $\mathrm{p}=0.660$ \\
\hline & $\mathrm{r}=0.137$ & $\mathrm{r}=0.027$ & $\mathrm{r}=0.238$ & $\mathrm{r}=0.014$ & $\mathrm{r}=0.631$ & $\mathrm{r}=0.221$ & $\mathrm{r}=0.082$ & $\mathrm{r}=0.048$ \\
\hline
\end{tabular}

${ }^{*} \mathrm{p}$ is statistically significant if $\mathrm{p}<0.05$ and $\mathrm{r}$ is Pearson's correlation coefficient

Table 8. Pearson correlation coefficients of inflammatory mediators with Insulin sensitivity (sex-wise)

\begin{tabular}{|c|c|c|c|c|c|c|c|c|}
\hline \multirow[t]{2}{*}{ Inflammatory Mediators } & \multicolumn{2}{|c|}{ Insulin } & \multicolumn{2}{|c|}{ HOMA-IR } & \multicolumn{2}{|c|}{ Insulin } & \multicolumn{2}{|c|}{ HOMA-IR } \\
\hline & $\begin{array}{l}\text { Males } \\
\mathrm{n}=81\end{array}$ & $\begin{array}{c}\text { Females } \\
n=79\end{array}$ & $\begin{array}{l}\text { Males } \\
\mathrm{n}=81\end{array}$ & $\begin{array}{c}\text { Females } \\
n=79\end{array}$ & $\begin{array}{l}\text { Males } \\
\mathrm{n}=94\end{array}$ & $\begin{array}{c}\text { Females } \\
n=86\end{array}$ & $\begin{array}{c}\text { Males } \\
\mathrm{n}=94\end{array}$ & $\begin{array}{c}\text { Females } \\
n=86\end{array}$ \\
\hline \multirow[t]{2}{*}{ TNF- $\alpha$} & $* \mathrm{p}=0.007$ & $\mathrm{p}=0.008$ & $\mathrm{p}=0.009$ & $\mathrm{p}=0.005$ & $* \mathrm{p}=0.011$ & $\mathrm{p}=0.013$ & $\mathrm{p}=0.110$ & $\mathrm{p}=0.009$ \\
\hline & $*_{\mathrm{r}}=0.468$ & $\mathrm{r}=0.358$ & $\mathrm{r}=0.379$ & $\mathrm{r}=0.398$ & $*_{\mathrm{r}}=0.014$ & $\mathrm{r}=0.020$ & $\mathrm{r}=0.095$ & $\mathrm{r}=0.320$ \\
\hline \multirow[t]{2}{*}{ IL-6 } & $\mathrm{p}=0.264$ & $\mathrm{p}=0.225$ & $\mathrm{p}=0.082$ & $\mathrm{p}=0.955$ & $p=0.636$ & $p=0.791$ & $p=0.747$ & $\mathrm{p}=0.892$ \\
\hline & $\mathrm{r}=0.126$ & $\mathrm{r}=-0.138$ & $\mathrm{r}=0.194$ & $\mathrm{r}=0.006$ & $\mathrm{r}=-0.049$ & $\mathrm{r}=-0.029$ & $\mathrm{r}=-0.034$ & $\mathrm{r}=-0.015$ \\
\hline \multirow[t]{2}{*}{ CRP } & $\mathrm{p}=0.666$ & $\mathrm{p}=0.924$ & $\mathrm{p}=0.720$ & $p=0.564$ & $\mathrm{p}=0.008$ & $\mathrm{p}=0.552$ & $\mathrm{p}=0.046$ & $\mathrm{p}=0.997$ \\
\hline & $\mathrm{r}=-0.049$ & $\mathrm{r}=-0.011$ & $\mathrm{r}=-0.040$ & $\mathrm{r}=0.066$ & $\mathrm{r}=-0.271$ & $\mathrm{r}=-0.065$ & $\mathrm{r}=-0.207$ & $\mathrm{r}=0.000$ \\
\hline \multirow[t]{2}{*}{ WBC } & $\mathrm{p}=0.603$ & $\mathrm{p}=0.286$ & $\mathrm{p}=0.397$ & $\mathrm{p}=0.473$ & $\mathrm{p}=0.941$ & $\mathrm{p}=0.497$ & $\mathrm{p}=0.797$ & $\mathrm{p}=0.560$ \\
\hline & $\mathrm{r}=-0.059$ & $\mathrm{r}=0.121$ & $\mathrm{r}=0.095$ & $\mathrm{r}=0.082$ & $\mathrm{r}=-0.004$ & $\mathrm{r}=-0.074$ & $\mathrm{r}=0.027$ & $\mathrm{r}=-0.064$ \\
\hline
\end{tabular}

$* \mathrm{p}$ is statistically significant if $\mathrm{p}<0.05$ and $\mathrm{r}$ is Pearson's correlation coefficient 
Table 9. Pearson correlation coefficients of BMI with Inflammatory mediators in T2DM Cases and Healthy controls

\begin{tabular}{|c|c|c|c|c|}
\hline \multirow{2}{*}{$\begin{array}{l}\text { Variables } \\
\text { TNF- } \alpha\end{array}$} & \multicolumn{2}{|c|}{$\begin{array}{c}\text { T2DM CASES }(\mathrm{N}=160) \\
\text { BMI }\end{array}$} & \multicolumn{2}{|c|}{$\begin{array}{c}\text { Healthy controls }(\mathrm{N}=180) \\
\text { BMI }\end{array}$} \\
\hline & $* p=0.395$ & $* \mathrm{r}=-0.069$ & $\mathrm{p}=0.800$ & $\mathrm{r}=0.018$ \\
\hline IL-6 & $\mathrm{p}=0.397$ & $\mathrm{r}=-0.066$ & $\mathrm{p}=0.890$ & $\mathrm{r}=0.010$ \\
\hline CRP & $\mathrm{p}=0.894$ & $\mathrm{r}=-0.011$ & $\mathrm{p}=0.083$ & $\mathrm{r}=-0.130$ \\
\hline WBC & $\mathrm{p}=0.022$ & $\mathrm{r}=-0.181$ & $\mathrm{p}=0.935$ & $\mathrm{r}=-0.006$ \\
\hline
\end{tabular}

*p is statistically significant if $\mathrm{p}<0.05$ and $\mathrm{r}$ is Pearson's correlation coefficient

Correlation of inflammatory mediators with BMI in the study group

Table 9 shows the correlation of inflammatory mediators with anthropometric parameter $(\mathrm{BMI})$ within $\mathrm{T} 2 \mathrm{DM}$ cases and healthy controls and it was found that there was no any association between these parameters $(p<0.05)$.

\section{Discussion}

Worldwide, people are suffering from T2DM and it is projected to increase from the present 415 million people to 642 million by 2040 . In all developing countries, it was seen that the number of T2DM patients is increasing and $75 \%$ of people with T2DM are living in these developing countries (31). In this study, we observed that sociodemographic factors like education, lifestyle and smoking have significant associations with T2DM except for residence (urban and rural areas of the same geographical area) which had no substantial influence on the levels of inflammatory mediators of study like, TNF- $\alpha$, CRP, IL-6 and WBC. After a thorough literature review on the dynamics of T2DM and inflammatory mediators on the Kashmiri population, this is the first kind of study conducted in the mountainous valley of Kashmir on inflammatory mediators with T2DM while only limited related studies have been conducted in this subcontinent on T2DM. It is known for T2DM that the concentration of many proteins of the acute phase like (CRP, IL-6 TNF- $\alpha$ ) is increased and that this increase correlates with the development of characteristics associated with this condition (deficiency of insulin resistance (32). From the results, we infer that there were an increased expression of inflammatory markers (TNF- $\alpha$, IL-6, CRP and WBC) between cases and controls which supports the findings of Phosat et al. as they found in their study that there were greater risk of T2DM with higher levels of inflammatory mediators (33). On the comparison between sex-wise within the case group, it was observed that there was an elevation in levels of TNF- $\alpha$, IL- 6 and CRP in female T2DM cases as compared to male T2DM cases which are in agreement with the findings of Insha et al., (32). There are many research studies on this subject which demonstrat that levels of markers of inflammatory reactions increased with the decrease in insulin sensitivity depending on the severity of T2DM (34). In this study, both male and female sexes have confirmed the importance of inflammatory mediators in the pathogenesis of T2DM. The levels of TNF- $\alpha$ rise significantly in both sexes compared to the control group showing correlation with glycemic profile and insulin sensitivity thus, being considered an independent predictor of the risk of developing T2DM (33).

Our study proved that only pro-inflammatory cytokine
TNF- $\alpha$ IL-6, could leads to the pathogenesis of T2DM while other inflammatory cytokines show negative and weak correlations with T2DM. This research study showed vibrant changes in concentrations of proinflammatory cytokines, in T2DM. Our findings are in concurrence with the results of Samuel et al. which showed serum expression of candidate mediators (TNF- $\alpha$, IL-6 and CRP) are elevated in T2DM cases which are independent of physical activity and other risk factors (35). It is suggest that TNF- $\alpha$ is an important predictor for the development of T2DM for males and females, in both rural and urban populations of the Kashmir population. These results which support the hypothesis that systemic inflammation is a common precursor for T2DM $(24,25$, $35)$.

Interestingly, the results of our study showed a high degree of correlation between these promising cytokines (CRP, TNF and IL-6, WBC) and BMI and showed increased levels of these candidate cytokines (WBC, CRP, TNF- $\alpha$, IL-6) in T2DM in comparison to healthy controls. The results are statically significant. Hence, our study support in this ethnic population of Kashmir valley that TNF- $\alpha$ inflammatory mediator's association and correlation are higher in T2DM cases as compared to controls, which somehow in mechanism create insulin resistance and predispose patients to T2DM if not treated at an early stage. IL-6 Inflammatory marker shows a weak correlation with T2DM (36). As we know, IL-6 has a pleiotropic nature that can act as an anti-inflammatory agent. In this case-control study, we found in our T2DM cases a significantly higher concentration of TNF- $\alpha$ as compared to those of controls which may be the possible cause of lowgrade inflammation and predisposed subjects to the T2DM or towards its complications. These assertions aggress with the findings of AL-Shukaili et al. (37). Furthermore, our experimental finding provides evidence that the pattern and variation of these cytokines (TNF- $\alpha$, IL-6, CRP and $\mathrm{WBC}$ ) are important in the pathogenesis of T2DM. The significant correlation of TNF- $\alpha$ inflammatory mediator in T2DM cases with glycemic profile and insulin sensitivity leads to the pathogenesis of diseases in this ethnic population. These findings are in agreement with the fact that inflammatory reactions depend on the group of cytokines rather than a single one. The role of inflammation in the pathogenesis of T2DM has been elucidated in several studies in different populations (36-38). Furthermore, investigations of these cytokine inflammatory mediators in this population is needed to establish their importance both as early biomarkers and diagnostic predictors for T2DM. 


\section{Conclusion}

Our data confirms that TNF- $\alpha$, IL-6, inflammatory mediator i.e., cytokines, plays a positive role in the pathogenesis of T2DM in this ethnic population of Kashmir and can act as early prediction biomarkers which can prevent T2DM in this population. Further studies on the wider range of these inflammatory mediators in association with other biochemical, immunoassay and hematological parameters are needed to establish role of inflammatory markers as early prediction biomarkers which can prevent T2DM in this population.

\section{Conflict of Interests}

The authors declare that they have no competing interests.

\section{References}

1. Rashid T, Bhat SA, Urfan Wani M, Majid S, Hassan I, Rashid S, et al. The lipid peroxidation and antioxidant status of type 2 diabetic patients in Kashmir (India). Int J Diabetes Dev Ctries. 2015;34:476-481

2. World Health Organization. Global health estimates: deaths by cause, age, sex and country, 2000-2012. Geneva: WHO; 2014

3. Farooq R, Majid S, Bhat SA, Amin Sh, Bhat MH, Wani HA, et al. Association of adiponectin gene polymorphism with type 2 diabetes and metabolic syndrome. Transl Meta Syndr Resear. 2018;1:39e47.

4. Waqas S, Tahir A, Nadeem S B, Mohammad R, Abdul H. Effect of diet on type 2 diabetes mellitus: A review. IJHS. 2017;11(2):22.

5. Bhat MA, Bhat SA, Ahmad SB, Qureshi W, Majid S, Ali A. Biochemical Profile and Genetic Polymorphism of MTHFRC677T in Risk of Type 2 Diabetes Mellituss. Int J Diabetes Endocrinol. 2017;2:2:19-25.

6. Ali A, Ayaz A, Dar MA, Singh N, Bhat SA. A Key Role of Insulin in Diabetes Mellitus. Int J Sci Res Sci. 2017;3(6):80-85.

7. Singh PS, Sharma H, Zafar KS, Singh PK, Yadav SK, Gautam RK. Prevalence of type 2 diabetes mellitus in rural population of India- a study from Western Uttar Pradesh. Int J Res Med Sci. 2017;5(4):1363-1367.

8. VinodMahato R, Gyawali P, Raut PP, Regmi P. Association between glycaemic control and serum lipid profile in type 2 diabetic patients: Glycated haemoglobin as a dual biomarker. Biomed Res 2011;22(3):375-380.

9. Iqra H, Shariq RM, Shahnaz AM, Mudasar N, Khalid G, Bashir AG. Type 2 diabetes mellitus: From a metabolic disorder to an inflammatory condition. World J Diabetes. 2015 May 15;6(4):598-612.

10. Esser N, Legrand-Poels S, Piette J, Scheen AJ, Paquot N. Inflammation as a link between obesity, metabolic syndrome and type $2 \mathrm{di}$ abetes. Diabetes Res Clin Pract. 2014;105:141-50.

11. Arora P, Garcia-Bailo B, Dastani Z, Brenner D, Villegas A, Malik $\mathrm{S}$, et al. Genetic polymorphisms of innate immunity-related inflammatory pathways and their association with factors related to type 2 diabetes. BMC Med Genet. 2011;12:95.

12. Belfki H, Ben Ali S, Bougatef S, Ben Ahmed D, Haddad N, Jmal A, et al. Association between C-reactive protein and type 2 diabetes in a Tunisian population. Inflammation. 2012;35:684-9.

13. Dongway AC, Faggad AS, Zaki HY, Abdalla BE. C-reactive protein is associated with low-density lipoprotein cholesterol and obesity in type 2 diabetic Sudanese. Diabetes Metab Syndr Obes. 2015;8:427-35.

14. Wang X, Bao W, Liu J, Ouyang YY, Wang D, Rong S, et al. Inflammatory markers and risk of type 2 diabetes: a systematic review and meta-analysis. Diabetes Care. 2013;36(1):166-75.

15. Pan A, Wang Y, Yuan JM, Koh WP. High-sensitive C-reactive protein and risk of incident type 2 diabetes: a case-control study nested within the Singapore Chinese Health Study. BMC Endocrinol Disord. 2017;17:8

16. Pradhan AD, Manson JE, Rifai N, Buring JE, Ridker PM. CReactive Protein, Interleukin 6, and Risk of Developing Type 2 Diabetes Mellitus. JAMA. 2018;286(3):327-334.

17. Smitka K, Maresova D. Adipose Tissue as an Endocrine Organ: An Update on Pro-inflammatory and Anti-inflammatory Microenvironment. Prague Med Rep. 2015;116:2;87-111.
18. Ibfelt T, Fischer CP, Plomgaard P, van Hall G, Pedersen BK. The acute effects of low-dose TNF-alpha on glucose metabolism and beta-cell function in humans. Mediat Inflamm. 2014;2014:295478.

19. Hajer GR, van Haeften TW, Visseren FL. Adipose tissue dysfunction in obesity, diabetes, and vascular diseases. Eur Heart J. 2008;29:2959-71.

20. Akbari M, Hassan-Zadeh V. IL-6 signalling pathways and the development of type 2 diabetes. Inflammopharmacology. 2018 Jun;26(3):685-698.

21. Popko K, Gorska E, Stelmaszczyk-Emmel A, Plywaczewski R, Stoklosa S, Gorecka D, et al. Proinflammatory cytokines IL-6 and TNF- $\alpha$ and the development of inflammation in obese subjects. Eur J Med Res. 2010;15:120-2.

22. Banerjee M, Saxena M. Genetic polymorphisms of cytokine genes in type 2 diabetes mellitus. World J Diabetes. 2014;5:493-504.

23. Lukic L, Lalic NM, Rajkovic N, Jotic A, Lalic K, Milicic T, et al Hypertension in obese type 2 diabetes patients is associated with increases in insulin resistance and IL-6 cytokine levels: potential targets for an efficient preventive intervention. Int $\mathrm{J}$ Environ Res Public Health. 2014;11(4):3586-98.

24. Xia W, Wei B, Jun L, Ying-Ying O, Di W, Shuang R, et al. Inflammatory markers and risk of type 2 diabetes: a systemic review and meta-analysis. Diabetes Care. 2013;36:166-75.

25. Nadeem A, Naveed AK, Hussain MM, Raza SI. Correlation of inflammatory markers with type 2 Diabetes Mellitus in Pakistani patients. J Postgrad Med Instit (Peshawar-Pakistan). 2013;27:03;267-273.

26. Deepika S. Culture and Social Dynamics of Food Patterning among Kashmiris: A Study in Srinagar and Jammu Districts. PhD thesis, University of Jammu, 2014.

27. Singh U. Prevalence of diabetes and other health related problems across India and worldwide: An overview. J Nat Appl Sci 2016;8(1):500-505.

28. Bertoni AG, Burke GL, Owusu JA, Carnethon MR, Vaidya D, Barr $\mathrm{RG}$, et al. Inflammation and the incidence of type 2 diabetes: the Multi-Ethnic Study of Atherosclerosis (MESA). Diabetes Care 2010;33:804-10.

29. Krakoff J, Funahashi T, Stehouwer CD, Schalkwijk CG, Tanaka S, Matsuzawa $\mathrm{Y}$, et al. Inflammatory markers, adiponectin, and risk of type 2 diabetes in the Pima Indian. Diabetes Care. 2003;26:1745-51.

30. Pradhan AD, Manson JE, Rifai N, Buring JE, Ridker PM. Creactive protein, interleukin 6 , and risk of developing type 2 diabetes mellitus. JAMA. 2001; 286:327-34.

31. Basanagouda Biradar S, Sangaraj Desai A, Virupaxappa Kashinakunti S, Rangappa M, Shantappa Kallaganada G, et al. Correlation between glycemic control markers and lipid profile in type 2 diabetes mellitus and impaired glucose tolerance. Int J Adv Med. 2018 Aug;5(4):832-837.

32. Inshah D, Sabhiya M, Fouzia R, Rabia F, Jasiya Q, Rouf M , et al. Combinatorial effect of leptin, tumor necrosis factor- $\alpha$ lpha, and vitamin $\mathrm{D}$ in progression of type 2 diabetes in Kashmiri population. Asian J Pharm Clin Res. 2018; 10(11):477-482.

33. Phosat C, Panprathip P, Chumpathat N, Prangpthip P, Chantratita $\mathrm{N}$, Soonthornworasiri N, et al. Elevated C-reactive protein, interleukin 6, tumor necrosis factor alpha and glycemic load associated with type 2 diabetes mellitus in rural Thais: a cross-sectional study. BMC Endocr Disord. 2017;17(1):44

34. Lukic L, Lalic NM, Rajkovic N, Jotic A, Lalic K, Milicic T, et al. Hypertension in obese type 2 diabetes patients is associated with increases in insulin resistance and IL-6 cytokine levels: potential targets for an efficient preventive intervention. Int $\mathrm{J}$ Environ Res Public Health. 2014;11:4:3586-98.

35. Samuel ND, Denis DY, Ellis OD, Dark SN, Yar D, Owasu D, et al. Variations in levels of IL- 6 and TNF- $\alpha$ in type 2 diabetes mellitus between rural and urban Ashanti Region of Ghana. BMC Endocrinol Disord. 2015;15:50:1-7.

36. Xia W, Wei B, Jun L, Ying-Ying O, Di W, Shuang R, et al. Inflammatory markers and risk of type 2 diabetes: a systemic review and meta-analysis. Diabetes Care. 2013;36:166-75.

37. Al-Shukaili A, AL-Ghafri S, Al-Marhoobi S, Al-Abri S, Al-Lawati $\mathrm{J}$, Al-Maskari M. Analysis of inflammatory mediators in type 2 diabetes patients. Int J Endocrinol. 2013;2013.

38. Marques-Vidal P, Bochud M, Bastardot F, Lüscher T, Ferrero F, Gaspoz JM. Association between Inflammatory and Obesity Markers in a Swiss Population-Based Sample (CoLaus Study). Obes Facts. 2012;5:734-744. 